\title{
Semi-Closed Method as Alternative to Open and Closed Methods for the Treatment of Pilonidal Sinus Disease
}

\author{
Hatem EIGohary, MD; MRCS \\ Department of General Surgery, Helwan University, Egypt
}

Introduction: Pilonidal sinus is a chronic recurrent disease of young adults and males are affected twice than females. Principles of surgery include complete eradication of the sinus tract; complete healing of the overlying skin, and prevention of recurrence, In this study, we used a semi-closed method, and we aimed to compare it with the open and Karydakis methods.

Patients and methods: Between January 2012 and March 2014, this prospective study included 148 patients with primary pilonidal sinus disease who were divided into three groups; group 1 (Karydakis method), group 2 (open method) and group 3 (semi-closed method). Outcome measures were operative time, length of hospital stay, rate of complications, time to return to work, time to complete wound healing, and recurrence rate.

Results: The mean operative time in group 1 was $55 \pm 5$ minutes. On the other hand, it was $32 \pm 8.11$ minutes in group 2 and $36.4 \pm 3.59$ minutes in group 3 (P 0.000). Healing time was significantly longer in the group treated by open method followed by semi-closed method and lastly Karydakis method with mean of $47 \pm 4.34,22.22 \pm 7.63$ days and $13 \pm 3.23$ respectively ( $P 0.000$ ). There were no significant differences between the three groups regarding postoperative complications except for seroma formation which was recorded lower in group two and three than in group one (P 0.002).

Conclusion: Semi-closed method is a good surgical option for the treatment of pilonidal sinus disease in terms of being simple, faster tissue healing and having better cosmetic results with low complications rate.

Key words: Pilonidal sinus, open method, recurrence, wound infection, semi-closed method, Karydakis.

\section{Introduction}

Pilonidal sinus disease is a chronic, recurrent disease of young adults, mostly affecting the sacrococcygeal region on midline skin and males are affected twice than females. ${ }^{1}$ Surgery is the main treatment option, and up to $40 \%$ of patients develop recurrence and this high rate of recurrence has led to the development of wide range of surgical techniques. ${ }^{2}$

Principles of surgery include complete eradication of the sinus tract; complete healing of the overlying skin, and prevention of recurrence. The surgical wound may be left open to heal by secondary intention and advocates of this technique state that reduced wound tension decreases recurrence, or the wound may be closed to heal by primary intention and advocates of primary closure perceive benefits of faster tissue healing. Closed methods can be broadly categorized as midline closure techniques (with the wound lying within the natal cleft) or other techniques (where the wound is placed away from the midline e.g. Karydakis method). ${ }^{3}$

Asymmetric closure methods have a high wound infection rate, high recurrence rate, poor cosmetic results and subsequently prolonged wound healing. ${ }^{4,5}$ In this study, we used a semi-closed method, and we aimed to compare it with open and Karydakis methods in the surgical management of pilonidal sinus disease.

\section{Patients and methods}

This was a prospective randomized study that included 148 patients with chronic primary pilonidal sinus who underwent surgery from January 2012 to March 2014 in Ain Shams University students' hospital and Dar el Shefa hospital - Ministry of Health. All procedures were done by the same surgeons after obtaining written consent for enrollment in this study and hospital ethical committee approval.

Patients were divided into three groups, group 1 included 42 patients (Karydakis method), group 2 included 57 patients (Open method) and group 3 included 49 patients (Semi-closed method).

We included patients with primary pilonidal sinus disease and we excluded patients with pilonidal abscess or recurrent disease. Outcome measures were operative time, length of hospital stay, rate of complications, time to return to work, time to complete wound healing, and recurrence rate.

Data were collected, revised, coded and entered to the Statistical Package for Social Science (IBM SPSS) version 20. Qualitative data were presented as numbers and percentages while quantitative data were presented as mean, standard deviations and ranges. The comparison between three groups with qualitative data were done by using 
Chi-square test and/or Fisher exact test was used instead of Chi-square test when the expected count in any cell was found less than 5 . The comparison between three groups regarding quantitative data with parametric distribution was done by using Independent t-test. The confidence interval was set to $95 \%$ and the margin of error accepted was set to $5 \%$. So, the p-value was considered significant at the level of $<0.05$.

\section{Operative technique:}

All patients were operated on under spinal or general anesthesia, in prone position and a third generation cephalosporin was used as premedication administered half an hour before surgery. The visibility of the intergluteal area was maintained by lateral traction from the lateral margin of the gluteus using adhesive tape.

In group 1 (Karydakis method), the sinus was probed by a medium sized cannula and Methylene blue dye was injected and left for five minutes to stain the sinus. Then the sinus was excised in asymmetrical ellipse reaching the sacral fascia with care taken not to open the sinus or to leave behind tissues stained with Methylene blue. Hemostasis was secured with electrical diathermy and skin flaps were done to ensure closure of the wound without tension away from midline. The subcutaneous fat was closed in layers using absorbable suture (Polyglactin 0 ) and the skin was closed by interrupted mattress stitches using polypropylene $3 / 0$ after insertion of subcutaneous suction drain. ${ }^{6}$

In the other two groups, the sinus was probed, layed open, curetted and then completely excised under vision and hemostasis was achieved using electro cautery (Figures 1a,b).

In group 2 (open method), the wound was left open and then packed by betadine gauze. In the semi-closed method, the subcutaneous fat was approximated by full thickness subcutaneous inverted stitches using absorbable suture (Polyglactin 0) leaving the skin open and the wound in the midline (Figure 2).

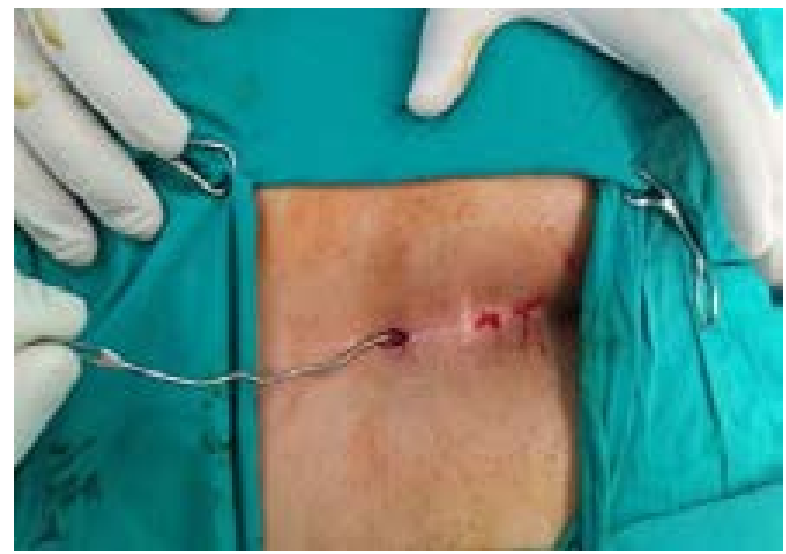

Fig 1A: Probing of Pilonidal sinus.

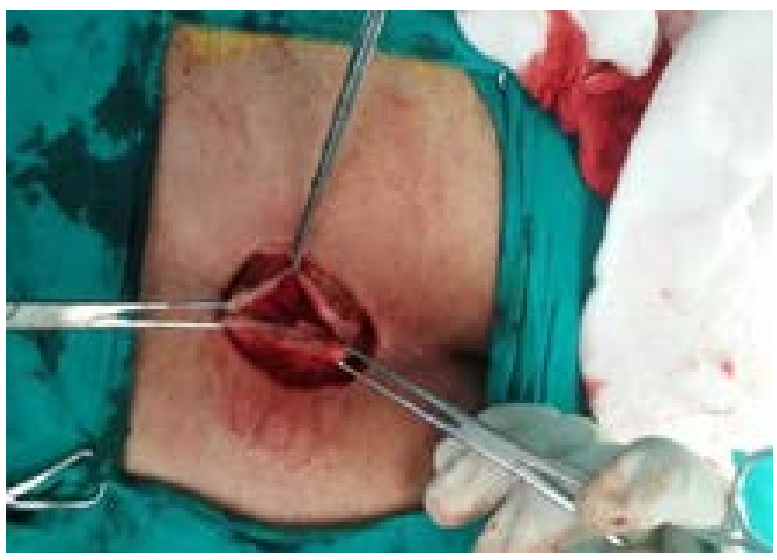

Fig 1B: Limited excision of the sinus track.

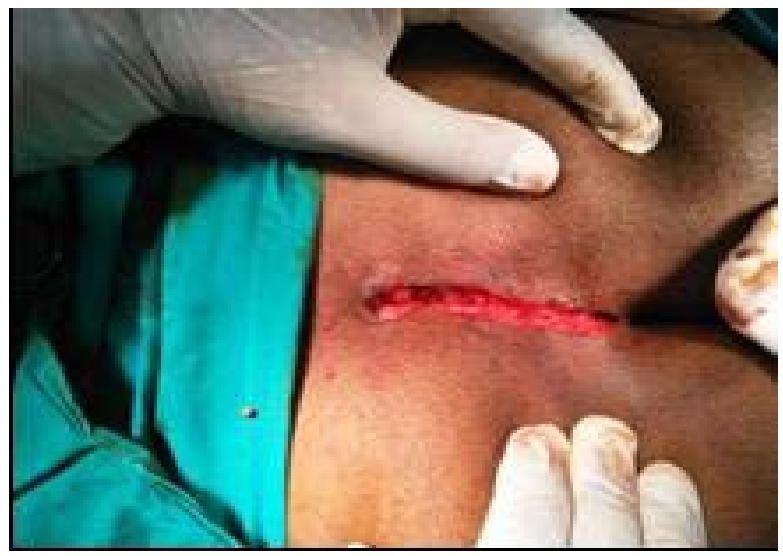

Fig 2: Wound after partial closure with full thickness subcutaneous sutures.

All patients had dressing on the $2^{\text {nd }}$ postoperative day using betadine solution. Stitches in Karydakis group were removed from the $10^{\text {th }}$ to the $14^{\text {th }}$ day postoperative according to healing and suction drain was removed when it drained less than $50 \mathrm{cc}$ per day. Stitches were removed earlier if any signs of infection appeared such as wound redness, purulent discharge or swelling. The Follow up visits in outpatient clinic was done weekly for 2 months and then monthly for one year and the least follow up was 1 year.

\section{Results}

Out of the 148 patients in this study, 102 (69\%) were males and $46(31 \%)$ were females with male to female ration being 2.2:1. The age ranged from $15-40$ years with mean of $23.5 \pm 10.3$ years in group $1,22.8 \pm 11.3$ years in group 2 and $23.15 \pm 10.8$ years in group 3 ( $P$ 0.339).

The mean BMI were 25.5 $\pm 3.75,27.3 \pm 4.27$ and 27.5 \pm 4.37 for group 1 , group 2 and group 3 respectively ( $P$ 0.046). (Table $\mathbf{1}$ ). 
Table 1: Age distribution

\begin{tabular}{|c|c|c|c|c|c|c|c|c|}
\hline Age & $\begin{array}{c}\text { Group1 } \\
\text { Karydakis } \\
\text { method } \\
(n=42)\end{array}$ & $\begin{array}{c}\text { Group2 } \\
\text { Open method } \\
(n=57)\end{array}$ & $\begin{array}{c}\text { Group3 } \\
\text { Semi } \\
\text { closed method } \\
(n=49)\end{array}$ & $\begin{array}{c}\text { Total } \\
(n=148)\end{array}$ & $\begin{array}{c}\text { Over } \\
\text { all pvalue }\end{array}$ & P1* & P3\# & P3\# \\
\hline $15-20$ & 5 & 11 & 10 & 26 & & & & \\
\hline $21-25$ & 18 & 25 & 19 & 62 & & & & \\
\hline $26-30$ & 2 & 8 & 8 & 18 & 0.339 & 0.133 & 0.165 & 0.982 \\
\hline $31-35$ & 15 & 9 & 9 & 33 & & & & \\
\hline $36-40$ & 2 & 4 & 3 & 9 & & & & \\
\hline Mean \pm SD & $25.5 \pm 3.75$ & $22.8 \pm 11.3$ & $23.15 \pm 10.8$ & & 0.951 & 0.753 & 0.875 & 0.871 \\
\hline BMI Mean \pm SD & $25.5 \pm 3.75$ & $27.3 \pm 4.27$ & $27.5 \pm 4.37$ & & 0.046 & 0.037 & 0.023 & 0.813 \\
\hline
\end{tabular}

*P1: Group 1 versus group 2 †P2: Group 1 versus group 3 fP3: Group 2 versus group 3.

The operative time ranged from 40 to 60 minutes in group 1 with a mean of $55 \pm 5$ minutes. On the other hand, it ranged from 30 to 40 minutes in group 2 with a mean of $32 \pm 8.11$ minutes and in group 3 ranged from 40 to 50 minutes with a mean of $36.4 \pm 3.59$ (P 0.000). The mean of hospital stay in group 1 was $1 \pm 0.15$ days, $1.7 \pm 0.4$ day in group 2 and $1.0 \pm 0.2$ in group 3 (P 0.000).
Healing time was significantly longer in the group treated by open method followed by semiclosed method and lastly Karydakis method with mean of $47 \pm 4.34,22.22 \pm 7.63$ days and $13 \pm 3.23$ respectively ( $P$ 0.000). The mean of time to return to work was $14 \pm 2.54$ days in group $1,50 \pm 3.33$ in group 2 and $23.88 \pm 5.26$ in group 3 (P 0.000$)$ (Table 2).

Table 2: Operative time, hospital stay, healing time and time to return to work

\begin{tabular}{|c|c|c|c|c|c|c|c|}
\hline & $\begin{array}{c}\text { Group1 } \\
\text { Karydakis } \\
\text { method } \\
(n=42)\end{array}$ & $\begin{array}{l}\text { Group2 } \\
\text { Open } \\
\text { method } \\
(n=57)\end{array}$ & $\begin{array}{c}\text { Group } 3 \\
\text { Semi- } \\
\text { closed } \\
\text { method } \\
(n=49)\end{array}$ & $\begin{array}{l}\mathbf{P} \\
\text { value }\end{array}$ & P1* & P3キ & P3\# \\
\hline Operative time by minutes & $55 \pm 5$ & $32 \pm 8.11$ & $36.40 \pm 3.59$ & 0.000 & 0.000 & 0.000 & 0.001 \\
\hline Hosp stay by days & $1 \pm 0.15$ & $1.7 \pm 0.4$ & $1.0 \pm 0.2$ & 0.000 & 0.000 & 1.000 & 0.000 \\
\hline Healing time by days & $13 \pm 3.23$ & $47 \pm 4.34$ & $\underset{7.63}{22.22} \pm$ & 0.000 & 0.000 & 0.000 & 0.000 \\
\hline $\begin{array}{l}\text { Time to return to work by } \\
\text { days }\end{array}$ & $14 \pm 2.54$ & $50 \pm 3.33$ & $\underset{5.26}{23.88} \pm$ & 0.000 & 0.000 & 0.000 & 0.000 \\
\hline
\end{tabular}

*P1: Group 1 versus group 2. †P2: Group 1 versus group. ¥P3: Group 2 versus group 3.

Complications reported in this study were in the form of wound infection, postoperative bleeding and recurrence. 4 patients (9.52\%) in group 1 had wound infection compared to $2(3.51 \%)$ patients in group 2 and $3(6.12 \%)$ in group 3 (P 0.465). Postoperative bleeding occurred in 1 patient $(2.38 \%)$ in group 1,4 patients $(7.02 \%)$ in group 2 and 1 patient $(2.04 \%)$ in group 3 ( $P$ 0.349).
The bleeding ranged from $100-200 \mathrm{cc}$ and in all patients was controlled by manual pressure and packing with dry gauze.

Recurrences reported during the one year follow up were 2 patients $(4.76 \%)$ in group 1,1 patient in group $2(1.75 \%)$ and 1 patient in group $3(2.04 \%)$ (P 0.620) (Table 3).

Table 3: Postoperative complications

\begin{tabular}{|c|c|c|c|c|c|c|c|c|c|c|}
\hline & \multicolumn{2}{|c|}{$\begin{array}{c}\text { Group1 } \\
\text { Karydakis } \\
\text { method } \\
(n=42)\end{array}$} & \multicolumn{2}{|c|}{$\begin{array}{l}\text { Group2 } \\
\text { Open } \\
\text { method } \\
(n=57)\end{array}$} & \multicolumn{2}{|c|}{$\begin{array}{c}\text { Group } 3 \\
\text { Semi-closed } \\
\text { method } \\
(n=49)\end{array}$} & \multirow[t]{2}{*}{$\begin{array}{c}P \\
\text { value }\end{array}$} & \multirow[t]{2}{*}{ P1* } & \multirow[t]{2}{*}{ P3\# } & \multirow[t]{2}{*}{ P3F } \\
\hline & No. & $\%$ & No. & $\%$ & No. & $\%$ & & & & \\
\hline $\begin{array}{l}\text { Wound } \\
\text { infection }\end{array}$ & 4 & $9.52 \%$ & 2 & $3.51 \%$ & 3 & $6.12 \%$ & 0.465 & 0.215 & 0.544 & 0.527 \\
\hline Seroma & 6 & $14.29 \%$ & 0 & $0.00 \%$ & 1 & $2.04 \%$ & 0.002 & 0.003 & 0.029 & 0.279 \\
\hline Postoperative bleeding & 1 & $2.38 \%$ & 4 & $7.02 \%$ & 1 & $2.04 \%$ & 0.349 & 0.297 & 0.913 & 0.228 \\
\hline Recurrence & 2 & $4.76 \%$ & 1 & $1.75 \%$ & 1 & 0.465 & 0.620 & 0.388 & 0.469 & 0.913 \\
\hline
\end{tabular}

*P1: Group 1 versus group 2. †P2: Group 1 versus group 3. ¥P3: Group 2 versus group 3. 


\section{Discussion}

Although pilonidal sinus disease cannot be considered a hazardous disabling disease, but its management carries a wide range of debate till nowadays. The best surgical technique for pilonidal disease should be simple, with short operative time, short recovery time, and low incidence of complications specially the recurrence rate. ${ }^{7}$ In this study, the operative time in Karydakis method was significantly longer than the open and semi-closed methods and this is because in Karydakis method, there was time added to inject methylene blue dye and to wait for tissue staining and time added in fashioning of flaps and skin closure (P 0.000). In a study done by Sakr, the operative time recorded in Karydakis method was $43.2 \pm 8.9$ minutes. ${ }^{8}$ In a study done by Lasheen et al, the mean operative time for the partial closure technique was 30 minutes which is almost similar to our results in the semi-closed method. ${ }^{9}$

Nowadays, pilonidal sinus surgery is a one day case procedure. The hospital stay in this study was longer in the open method group than in the other two groups, with mean of $1.7 \pm 0.4$ day and this is explained because $7 \%$ of patients were complicated by postoperative bleeding which in turn prolonged their hospital stay (P 0.349).

Leaving pilonidal wounds to heal by secondary intention avoids a reconstructive procedure but increases the time of healing. Closure of wounds has been shown in a Cochrane review published in 2010 to have a higher incidence of recurrence compared with open methods. ${ }^{10}$ In our study, the healing time and time to return to work were significantly shortened in the Karydakis group than in the other two groups, with the semi-closed method in the midway (P 0.000). Shah found in their study that the mean healing time for open method was $7.1563 \pm 1.0602$ weeks and 2.78 \pm 0.6993 weeks for the closed method. ${ }^{11}$

Probing of the pilonidal sinus and then laying it open, facilitates full visualization and excision of the sinus and all of its branched tracks which in turn decrease recurrence and we suggest that it may not be achieved in Karydakis method when removing closed tissue ellipse containing the track.

Moreover, it avoids over excision of normal tissue around the sinus leaving large wound to be closed under tension and large flaps to be raised.

Wound infection was higher in the Karydakis group and the infection was found mainly at the lower end of the wound close to the anal verge, mostly due to contamination. Higher BMI in patients of group 1, subcutaneous flaps and formation of closed space in comparison to the other groups played a significant role in seroma collection, and it was recorded as the lowest in the open method group ( $P$ 0.002). Wound infection was treated by local antibiotics ointments and twice daily dressing with betadine solution and early stitches removal. In addition to proper drainage of seroma once detected, two patients in Karydakis group (4\%) had recurrence and one patient in each of the other groups during one year follow up (P 0.620). Lasheen et al, reported recurrence in one case $(1.5 \%)$ out of 67 patients included in their study who underwent partial closure technique. ${ }^{8}$ Whilst M. Kamil Yildiz et al reported $2.3 \%$ recurrence rate using Karydakis method. ${ }^{12}$ Moreover, the most accepted cosmetic results were found in the group treated by semi-closed method because it kept the wound in the midline preserving the natal cleft and the disfigurement was less than in patients with the open method.

\section{Conclusion}

Semi-closed technique is a good surgical option for pilonidal sinus disease in terms of being simple, faster wound healing, low complications rate and good cosmetic result. However, we recommend having more studies on a bigger number of patients with longer follow-up periods in order to support our results for using this technique.

\section{References}

1. Petersen S, Aumann G, Kramer A, Doll D, Sailer $M$, Hellmich G: Short-term results of Karydakis flap for pilonidal sinus disease. Techniques in Coloproctology 2007; 11: 235-240.

2. Müller $\mathrm{K} 1$, Marti $\mathrm{L}$, Tarantino I, Jayne DG, Wolff $\mathrm{K}$, Hetzer FH: Prospective analysis of cosmesis, morbidity, and patient satisfaction following Limberg flap for the treatment of sacrococcygeal pilonidal sinus. Dis Colon Rectum 2011; 54: 487-494.

3. McCallum I, King PM, Bruce J: Healing by primary versus secondary intention after surgical treatment for pilonidal sinus. Systematic review and meta-analysis. BMJ 2008; 336: 868-871.

4. Holmebakk T, Nesbakken A: Surgery for pilonidal disease. Scand J surg 2005; 94: 4346.

5. Rushfeldt C, Bernstein A, Norderval S, Revhaug A: Introducing an asymmetric cleft lift technique as a uniform procedure for pilonidal sinus surgery. Scand J surg 2008; 97: 77-81.

6. Karydakis GE: Easy and successful treatment of pilonidal sinus after explanation of its causative process. Aust $\boldsymbol{N} \boldsymbol{Z} \boldsymbol{J}$ Surg 1992; 62: 
385-389.

7. Gençosmanoğlu R, Inceoglu R: Modified layopen (incision, curettage, partial lateral wall excision and marsupialization) versus total excision with primary closure in the treatment of chronic sacrococcygeal pilonidal sinus. A prospective, randomized clinical trial with a complete two-year follow-up. Int J Colorectal Dis 2005; 20: 415-422.

8. Sakr MF, Elserafy ME, Hamed HM, Ramadan MA, Kantoush HE, El-Torky HM: Management of 634 Consecutive patients with chronic pilonidal sinus. A nine-year experience of a single institute. Surgical Science 2012; 3: 145-154.

9. Lasheen A, Safwat K, Morsy M, Fiad A, Elmoregy AW: Excision and partial primary closure of wound for pilonidal disease. Egypt Surgical Science 2012; 3: 366-370.
10. Al-Khamis A, McCallum I, King PM, Bruce $\mathrm{J}$ : Healing by primary versus secondary intention after surgical treatment for pilonidal sinus. Cochrane Database Syst Rev 2010; 20: (1): CD006213. Doi: 10.1002/14651858. CD006213.

11. Shah STA, Tahir M, Nasir M, Paracha SA, Wahab K: Outcome of open versus closed technique for surgical treatment of chronic pilonidal sinus. A randomized controlled trial. Khyber Med Univ J 2013; 5: 146-151.

12. Kamil Yildiz M, Erkan Ozkan, Hacı Mehmet Odabaşı, Bülent Kaya, Cengiz Eriş, Hacı Hasan Abuoğlu, et al: Karydakis Flap Procedure in Patients with Sacrococcygeal Pilonidal Sinus Disease. Experience of a Single Centre in Istanbul. The Scientific World Journal 2013; Article ID 807027, 4 pages. 